\title{
NADERE MEDEDEELINGEN OVER DEN OPSTAND VAN SAPAROEA IN 1817.
}

Door P. H. VÁN DER KEMP.

I.

In deze Bijdragen wijdde ik een uitvoerigen arbeid aan "Het herstel van het Nederlandsch gezag in de Molukken in 1817", waartoe ook werd gebracht het bedwingen van den opstand in dat jaar: zie den jaargang van $1911 \mathrm{dl}$. $65 \mathrm{I}^{\mathrm{e}}$ en $\mathrm{II}^{\mathrm{e}}$ gedeelte, bl. 339-736 en dl. 66, III $^{\mathrm{e}}$ gedeelte, bl. 1-167.

Sinds ontmoette ik op het Algemeen Rijksarchief alhier in de z.g. Goldberg-verzameling (zie bl. 43 van het jaarverslag over 1902), nevens het afschrift van een verslag door Buijskes gericht aan den Koning over zijn expeditie, twee kaarten van het opstandsterrein: men kan de stukken vinden in de portefeuille $\mathrm{N}^{\circ} 15 \mathrm{D}$; het rapport verwijst echter niet naar die kaarten. De eene omvat het geheele terrein, ongeveer in den geest van die, welke reeds bij mijn verhandeling gevoegd werd; de andere geeft enkel weer het zuidelijk deel van het eiland Saparoea. Had ik ook gaarne eerstvermelde kaart gekend, vóór ik mijn vriend J. Habbema verzocht de aan mijn verhandeling toegevoegde samen te stellen, daar er aanwijzingen over de ligging van plaatsen op voorkomen, die mij van dienst badden kunnen zijn, ik heb nu geen voldoende aanleiding gevonden om het bestuur van het Instituut in overweging te geven alsnog kosten te maken voor het doen drukken van deze kaart. Iets anders is het echter met de Saparoea-teekening; ik achtte die bepaaldelijk van geschiedkundig belang, om redenen, die ik nog zal ontvouwen; het Instituutsbestuur heeft met mijn gevoelen wel willen medegaan, zoodat ik in de gelegenheid ben gesteld haar hiernevens over te leggen. Het stuk is met de legenda letterlijk afgenomen van het origineel, waarin ik dus D1. 69. 
ook geen enkele verandering van spelling aanbracht. Alleen voegde $\mathrm{ik}$ er vier aanwijzingen $\mathrm{bij}$, waarop ik nader terugkom en die niet op de Archiefkaart staan, te weten: Aer Oeroehpoetil, T. Paperoe, Aer Radja en Fonteintjes. De wijze van teekening doet vermoeden, dat een marine-officier de maker der kaart is geweest.

Behalve de hiervermelde stukken gewerden mij eenige andere gegevens tot nadere verklaring van het in 1817 gebeurde en die ik nu ook gebruiken kan. Van geen verhandeling namelijk heb $\mathrm{ik}$, wat aangaat den indruk op den lezer, zooveel voldoening gehad als van die over de Molukken, blijkens onderscheidene warme waardeeringen, die mij in de meest aantrekkelijke wijze mochten geworden; niet enkel van hen, aan wie overdrukken waren gezonden, doch ook van anderen, waaronder mij persoonlijk onbekenden. Aldus ontving ik een schrijven van den heer G. J. van Wagensveld Jr., gedagteekend Apeldoorn, 4 December 1912 , waarin het volgende voorkomt: "Ik heb zelf ruim drie jaar op Saparoea doorgebracht en kon dus precies nagaan, hoe de verschillende gebeurtenissen hebben plaats gehad. Ik meen $U$ een genoegen te doen, $U$ een kaartje van het eiland te zenden en tevens eenige ophelderingen te geven. Ik had het te $\mathrm{S}$. al willen doen, maar door mijn vertrek naar Holland heb ik er geen tijd voor gehad." Zeer zeker heeft mij de toezending van dat kaartje benevens van de ophelderingen genoegen gedaan. De hiervoren vermelde vier aanwijzingen door mij gebracht op , de Buijskeskaart, ontleende ik alvast daaraan.

Wat betreft het rapport aan den Koning, Buijskes heeft na zijn terugkomst te Batavia d.d. 22 April 1818 - hij verliet Ambon d.d. 25 Februari t.v. - twee verslagen ingediend aan de Commissie-Generaal, die ik bereids publiceerde in de Molukkenverhandeling: één gedagteekend Kedong Allang, 10 October 1818, over de oorzaken van den opstand in dl. II, bl. 570 - 578; het ander gedagteekend Buitenzorg, 25 September 1818, over zijn expeditie in dl. III, bl. 129-149. Het afschrift-rapport aan den Koning heeft tot onderschrift: "Amboina den 24 Sept. 1818, Uwer Majesteit gehoorzame dienaar en getrouwe onderdaan geteekend A. A. Buijskes." Niet speciaal lettende op den datum, enkel afgaande op de plaatsaanwijzing, nam ik met eenige verwachting het stuk ter hand, omdat het op de plaats der actie en alzoo niet lang daarna geschreven zou zijn. Eerst bij 
de lezing trok, door de in vele opzichten met de vermelde verslagen gelijkluidende mededeelingen, mijn aandacht het foutieve van Amboina. Nochtans zijn er een paar mededeelingen in, die wel verdienen gekend te worden, waarom ik ze zal opnemen. Maar hoe is men aan dit anders verwarring stichtend Amboina gekomen? Het kan toch bezwaarlijk worden aangenomen, dat Buijskes zelf die fout in zijn rapport aan den Koning maakte. $\mathrm{Z}_{\mathrm{ij}}$ verlevendigde bij mij al de verdrietelijkheden, die ik reeds heb ondervonden van het voortdurend werken op slecht genomen afschriften. ${ }^{1}$

Bij de hieronder volgende mededeelingen, neem ik onderstaande verkortingen aan:

B. K.: de hierbij aangeboden kaart van Saparoea;

B. R.: het rapport van Buijskes aan den Koning;

M. : mijn Molukkenverhandeling;

M.K.: de daarbij gevoegde kaart;

W.: de brief van den heer Wagensveld;

W.K.: het daarbij aangeboden kaartje, dat ik echter hier niet overnam.

1 Mij gewerd dientengevolge eens een aanmerking over een in deze Bijdragen verschenen artikel, terwijl die aanmerking slechts kon treffen de wijze, waarop afschrift was genomen van een in Londen bewaard stuk. Karakteristiek is geweest, wat ik eenige maanden geleden heb ervaren. In het werk van M. L. van Deventer over het Nederlandsch gezag op Java "sinds 1811", zooals het heet, is opgenomen een aan Goldberg gerichte brief van Elout, geschreven tijdens de reis over Java in 1817. Dit schrijven vergelijkende met den brief op 's Rijks archief, ontwaarde ik een geheel anderen opzet; ik makkte er melding van in een noot van mijn dit jaar (1913) verschenen werk over het bestuur van C. C. G. G. Daarin deed ik andere brieven van die reis drukken en toen trof mij bij vergelijking voor de correctie van al het gedrukte met de reisbrieven in de Goldberg-verzameling aanwezig, niet alleen, dat een door mij opgenomen brief ook geheel onvolledig was teruggegeven, maar tevens, dat op Van Deventer's brief geen aanmerking viel te maken. Alles moest nu weer herdrukt worden!! Een weinig beduidende aanteekening in mijn papieren wijst er op, hoe dat misverstand, naar ik denk, zal zijn ontstaan. De reisbrieven van C. C. G. G. liggen, teekende ik aan, op het Rijksarchief "in een bundeltje". Vóór jaren had ik daaruit geput en vond destijds de vergelijking met Van Deventer's bijlage plaats; doch dat bleken nu niet de brieven voorhanden in de Goldberg-verzameling, die door Elout geteekend, in meer dan één exemplaar soms, er bewaard worden. Ik vermoed dat de brieven van het "bundeltje" slecht genomen of willekeurig veranderde afschriften zijn. Wat ik hier mededeel, betreft de bijlagen XXX en XXXI van mijn werk en bijlage XLVI van Van Deventer's boek, aangehaald in mijn werk op bl. 389 , noot 3 . 
II.

a. Over de Beetjes-expeditie schreef ik (M. dl. II, bl. 611-612 dat de vloot was gezeild "tot op de hoogte van Paperoe" waarna ze overstak naar Wai Hanaia, "een kwartier beooste het fort Duurstede" en op de M. K. aangegeven, Volgens W wordt de plaats tegenwoordig geschreven Wä̈ Hennai(j) en uitgesproken met den klemtoon op $i$. - De branding he landen aldaar belettende, schepte men, schreef $\mathrm{ik}$, met aar haling van Van Doren, voorbij het fort, west op "naar Wa Sisi, eene kleine rivier tusschen Tiow en Paperoe", waar me uitstapte. De B. K. geeft nu inderdaad deze landingsplaats uif drukkelijk aan. Het Way Sisi moet echter volgens W. zijn Wae Sisil.

Deze landingsplaats beschreef ik, overeenkomstig de schriftureı er over, als "een moerassige grond": M. dl. II, bl. 613; il vond dit blijkens een noot aldaar nader bevestigd, door professo Martin. W. zegt echter hiervan: "Het is waar, dat daar ees moeras ligt, maar niet vlak aan de kust. Er ligt een $\pm 50 \mathrm{M}$ breede, harde karanggrond, maar daar achter een laagte, dis bij vloed door het indringende water onder komt te staan et bij eb weer droog loopt. Het water van de Wae Sisil is dar ook beslist zout." Ik moet intusschen er aan herinneren, da dergelijke bodemgesteldheden verbazend snel kunnen veranderen Kort vóór de Krakatau-ramp was ik assistent-resident van Tjeringir in Bantam aan de Soendastraat. Er bestond daar wel een karang. strand, doch niet waar ik dagelijks een zeebad nam; met der Westmoesson had ik er echter mede opgehouden: na een paas maanden er terugkomende, was het gansche strand door $\mathrm{d} \epsilon$ karang-aangroeiing of zandverplaatsing voor baden onbruikbaa geworden.

Toen Beetjes' troepen voor de overmacht moesten terug. wijken, vonden zij, schreef ik op gezag van Ver Huell (M. dl. II, bl. 618) de orembaais weg gedreven «door den aflandigen wind". Aan W. komt dit vreemd voor, daar in Mei de Oostmoesson reeds goed doorstaat; W. vermeent dat de vaartuigen door de eb zullen zijn afgedreven.

b. Toen Matulesi de orembaais zag naderen, gelastte hij, volgens het door mij genoemde inlandsche rapport-Porto, dat 
er wacht moest worden gehouden van "Uraputij tot Paperoe": M. dl. II, bl. 623; ik teekende daarbij aan, dat ik eerstgenoemde plaats niet kon thuisbrengen. Volgens W. is bedoeld Aer Oeroepoetih; oeroe beteekent hoofd. Het stroompje werd door hem aangegeven te liggen aan kaap Boi, ongeveer op de plaats, door mij op de B. K. vermeld. De vergelijking met de $\mathrm{W} . \mathrm{K}$. is echter eenigszins onzeker, omdat op de B. K. het Boische voorgebergte niet genoegzaam gerekt is geteekend.

De W.K. teekent het voorgebergte van Boi in met de volgende voor elkander van noord naar zuid liggende goenoengs:

Amaparoetol, op de breedte van Paperoe;

Amasano ;

Noesarino;

Toemawa, ongeveer op de breedte van negerij Boi; en

Hoe öe.

Ten westen hiervan stroomt zuidwaarts de Aer Oeroepoetih, in zee mondende ten westen van Tandjong Boi.

c. Over den lijdenstocht van resident Van den Berg op 15 Mei 1817, schreef het rapport-Porto, dat de menschen van Haria verzameld waren te "Ajer Radja"; een mij onbekende plaats, teekende ik daarbij aan: M. dl. II bl. 586. Blijkens de W.K. ligt zij ten noorden van den weg van Haria naar Tiow. Ik heb om de situatie ongevecr aan te geven, Ajer Radja op de B. K. geteekend, in verband met den daar zeer naar het noorden buigenden weg, waardoor echter de ligging wel wat te ver van Tiow schijnt. "'t Is een bron", schrijft W., "waarvan het water na een 50 M. stroomens weer in den berg verdwijnt. 't Water is prachtig helder en evenals dat der Fonteintjes niet kalkhoudend. 't Wordt veel als waschwater gebruikt."

Op dezelfde bladzijde 586, wordt in noot 6 melding gemaakt van een "oppasser van de kerk van Hario", gelijk is medegedeeld in Rapport-Porto, doch als "maringo = heerendienstplichtige". W. verbetert: "marinjo", dat men wordt, merkt hij op, om van heerendienst vrij te zijn, terwijl bovendien traktement door de negorij wordt gegeven in den vorm van sagokoekjes, klappers enz.

Nog op die bladzijde mak ik gewag van den regent van Siri Sori: Johannes Salomon Kirauly. W. wijst er op, dat de tegenwoordige regent heet Kesaulija, zoodat bij hem de vraag is gerezen of Kirauly wel juist zou zijn. Dit, dunkt mij, zou men wel door plaatselijke navraag te weten kunnen komen. 
Gelijk ik in M. dl. II, bl. 663, noot 1 memoreerde, komt herhaaldelijk in de scheepsstukken voor den naam van Passo Poetih, of, gelijk in Groot's scheepsjournaal Passir Poetih, een plaats, die ik weder niet kon thuis brengen. Volgens W. heeft men daarmede op het oog Tandjong Oemepoetih, dat hetzelfde is als Passo- of Passirpoetih en alzoo wit zand beteekent; het behoort tot de negorij Koelor. Dit Koelor (M. dl. I, bl. 469) vindt men op de M. K. aan den uitersten noordwesthoek van het eiland Saparoea; ten noorden daarvan heeft de W. K. bedoelde Tandjong.

d. Breedvoerig beschreef ik de expeditie van commandant Groot van de Reijgersbergen naar het landschap Hatawano op Saparoea: M. dl. II, bl. 658 v.v. Ik heb er tevens medegedeeld den door mij daarvan verkregen min gunstigen indruk, speciaal, wat betreft de onderhandelingsmanie, eindigende in Groot's persoonlijk aan wal gaan: "deze nieuwe waaghalzerij", schreef ik op bl. 686. In het B. R. staat erover: "het verscheelde weinig of deze officier had het slagtoffer van zijnen ijver en welwillendheid geweest", waaruit ik meen te mogen opmaken, dat ook de Schout-bij-nacht dien ijver en welwillendheid minder geschikt heeft gevonden.

Wat Groot aldus in reputatie mocht dreigen te verliezen, herstelde hij in ieder geval door de herneming van fort Duurstede d.d. 3 Augustus 1817: M. dl. II, bl. 706. Daar men intusschen niet verder op het eiland kwam, veeleer de bezetting door de rebellen als opgesloten werd, behoudens aan den zeekant, schreef ik daar, dat het wapenfeit voorloopig nog slechts van belang bleek "uit een oogpunt van moreelen indruk". Ofschoon ik daarbij wel een geopend oog had voor het belang dezer gebeurtenis ten aanzien van het eiland Haroekoe (M. dl. III, bl. 46), is toch tevens van waarde deze opmerking in het B. R.: "Dit hernemen en bezet houden van het fort Duurstede was echter van zeer veel belang, daar de muitelingen, verpligt zijnde hetzelve ingesloten te houden, zich niet naar de andere eilanden konden begeven. Dit was vooral gelukkig voor de post op Haroekoe, die reeds drie malen door eene groote overmagt was aangevallen geweest, doch door de bedaarde moed van den Kapitein (nu Majoor) van Driel en door het aanwezen van een ingehuurd gewapend scheepje is behouden gebleven." 
$e$. Toen de Commissie-Generaal het uitbreken van den opstand vernam, werd aanstonds het besluit van 25 Juni 1817 genomen (M. dl. III, bl. 5), waarbij Buijskes opgedragen werd naar de Molukken te gaan, dank diens "welwillende aanneming": zie het besluit in Brieven-Van de Graaff, dl. I, bl. 46. In het B. R. staat echter: op de tijding van den opstand "bood ik mijne ambtgenooten dadelijk aan, om $\mathrm{mij}$ in persoon naar derwaarts te begeven en had het genoegen te bespeuren, ik hierin hun verlangen was voorgekomen".

In M. dl. III, bl. 9 heb ik wel gewag gemaakt van de troepen, die Buijskes zouden vergezellen, doch niet categorisch medegedeeld, waaruit die eigenlijk bestonden. In B. R. leest men hierover: "Daar het ons bekend was dat het garnizoen van Amboina door het detacheren naar Ternate, Banda en verdere kleine posten zeer verzwakt was en de inlandsche militairen voor het grootste gedeelte nog slechts recruten waren, begrepen wij het vooral noodzakelijk zoude zijn eene versterking van geoefende militairen naar derwaarts te zenden. Twee kompagnien Europesche militairen van Batavia en eene kompagnie inlanders van Samarang, benevens een detachement artillerie van Sourabaija, werden ter mijner beschikking gesteld."

Niettegenstaande er zulk een haast was met de komst van Buijskes en zijn troepen op Amboina, heeft de Schout-bij-nacht met de Prins Frederik de reis gemaakt langs een omweg, namelijk door de straat van Makassar, terwijl alleen de twee vergezellende transportschepen Industrie en Patterson rechtstreeks naar Amboina zeilden. Verg. M. dl. III, bl. 10, laatste alinea en bl. 129 alinea 3 van het rapport aldaar. Dit heeft mij destijds reeds bevreemd; wij lezen nu echter in B. R. de volgende verklaring:

"Den 27 Julij embarkeerde ik mij op de Prins Frederik en zeilde die dag nog naar zee en daar het juist in het felst van de Oostmoesson was en dus in een jaargetijde, waarin men bevorens vermeende, onze schepen met geene mogelijkheid naar de Molukkos konden ophalen, resolveerde ik door straat Macassar te gaan, waardoor ik zekerder van de reis was.

"De twee ingehuurde transportschepen zond ik langs het zoogenoemd zuiderwater, alzoo zij zeer ondiep gaande, de tregter uit (of het oostgat van Sourabaija) naar zee konden zeilen en hadden het geluk van in het laatst van Augustus reeds op Amboina aan te komen." 
$f$. Nadat Buijskes eenigen tijd te Ternate verbleef en de beide vorsten aldaar tot het leveren van manschappen en 40 kora-kora's had verplicht, zeilde de Frederik mede naar Ambon. Niet geheel onbelangrijk is het, wat het B. R. mededeelt over den indruk, dien de Rapporteur heeft gekregen van de maatregelen genomen én door de heeren Engelhard en Van Middelkoop, én door den commandant van het eskader, kolonel Sloterdijk van de Nassau.

Ik memoreerde, dat Ver Huell van de Evertsen op het bericht van den opstand dadelijk naar Saparoea had willen zeilen, dat men dit ook goedgevonden had, doch dat hij tegenbevel kreeg; Engelhard de reden hiervan naar Batavia schrijvende, merkte ik daaromtrent op (M. dl. II, bl. 598): "Met de vrees voor zichzelf te Ambon is men eigenlijk niet voor den dag durven komen." Ver Huell in zijn Herinneringen had hetzelfde aldus zacht uitgedrukt: "Men wilde de hoofdplaats van den bijstand van een der groote schepen niet ontblooten." Maar het B. R. schrijft: "Men was dan ook in de grootste benauwdheid alhier op Amboina geweest, wijl men vreesde dat de ingezetenen van de Negerijen op Leytimore ook zich zouden tegen het gouvernement verklaren, zoodra de muitelingen slechts naderden; men had dus alle mogelijke voorzorg genomen, om dit hoofdkasteel in staat van defensie te stellen, en dat men geen der twee Linieschepen (: de Evertse en Nassau:) naar Saparoea had afgezonden, was, mijns bedunkens, om dezelve ten allen tijde disponibel te hebben, om daarmede te kunnen vlugten, ten minste alle genomen maatregelen hebben mij in dit denkbeeld bevestigd." 1

Sloterdijk was mede hiervoor verantwoordelijk. Onder den druk daarvan, terwijl de Frederik te vergeefs trachtte den $29^{\text {n }}$ September 1817 naar Ambon op te werken, maakte hij een einde aan zijn leven: M. dl. III, bl. 12-13. Het blijkt nu,

I Over Middelkoop's belachelijke houding en gemis aan oprechtheid, waarover Engelhard terecht klaagde, was ik in de M.-verhandeling breedvoerig. Het heeft sinds mijn aandacht getrokken, dat reeds over Van Middelkoop, als resident van Semarang onder Daendels als volgt werd geoordeeld door Nahuijs: „Het gedrag van onzen gastheer Middelkoop was bij deze gelegenheid inderdaad hoogst belachlijk, maar dezen oudgast, die voor niet zeer opregt werd gehouden, dubbel waardig." Herinneringen (1858), bl, 83 . 
dat hij dit gedaan heeft na ontvangst van Buijskes' adjudant; in het B. R. leest men toch: "Ongelukkig was de Kapitein Dietz. overleden en dus het kommando van $\mathrm{H}^{\mathrm{r}}$. $\mathrm{M}^{\mathrm{s}}$. schepen in de Molukkos op den Kapitein Sloterdijk vervallen, die daar niet voor berekend was en in welke officier ik mij zeer vergist heb. Dezelve heeft mijne komst niet afgewacht, maar zoodra mijn adjudant hem mijne nabijheid voor de baaij geannonceerd had, zich in de daarop volgende nacht doodgeschoten."

$g$. Tot commandant der nu volgende en door mij beschreven expeditiën naar Hitoe, Haroekoe en Saparoea, benoemde Buijskes majoor Meijer (M. dl. III, bl. 24 v.v.), "die", vermeldt het B. R., "bevorens zeeofficier geweest zijnde, zooals mij voorkomt, daar het best voor geschikt was".

Nassau en Evertsen werden door Buijskes gedirigeerd van Ambon naar de baai van Saparoea, de Reijgersbergen van de baai van Saparoea naar die van Haria. De B. K. geeft haar ligging duidelijk aan; speciaal, wat de laatste betreft van af 7 November 1817; wat de beide anderen aangaat van af den volgenden dag. Verg. M. dl. III, bl. 57 en 58. Mijn algemeene aanwijzing in M. dl. I, bl. 470: «Dicht bij den muur (van het fort) bevond zich het residentie-huis", wordt mede dank de vermelding der legenda $a$ verduidelijkt; ook de put van fort Duurstede, waarover zooveel te doen is geweest (M. dl. I, bl. 470 ; dl. II, bl. 706) wordt nu onder $d$ stellig aangewezen. En eindelijk memoreer ik den beslissenden dag van 9 November 1817, als uit fort Duurstede een expeditie plaats vond om de van Haria onder majoor Meijer aanrukkende troepen de hand te reiken, dat "men stiet voor een afgebrande brug": M. dl. III, bl. 61. Op de B.K. zien wij die brug vermeld staan onder $c$, waardoor wij ons het door mij daar en elders beschrevene helderder kunnen voorstellen. Hoe de ingeteekende rivier heet, wordt niet vermeld; zij stroomt tusschen de negorijen Tiow en Saparoea door; lettende verder op den loop van noord naar zuid, zoo zou ik aan de hand der W. K. vermeenen, dat de rivier heet Wae Mocla; blijkens M. dl. II, bl. 616 heette zij bij Van Doren, indien de daar bedoelde brug dezelfde is, Wai Sioel. Vermoedelijk zal bij het in M. dl. II, bl. 717 vermeld "bruggetje" en bij de op bl. 724 aldaar vermelde "drie bruggen", die verbrand werden, ook aan bovenvermelden overgang gedacht moeten worden. 
h. Ik maak van deze gelegenheid gebruik op een paar hinderlijke verschrijvingen in mijn Molukkenverhandeling de aandacht te vestigen:

dl. I, bl. 500, laatste alinea, staat 1820 ; m. z. 1810 ;

dl. III, bl. 56 en 57. Op eerstgenoemde bladzijde staat eenmaal, op laatstgenoemde tweemaal gedrukt Evertsen; m.z. Reijgersbergen.

dl. III, bl. 71, laatste alinea, staat "dat met de vermeestering van Tiow op den $10^{\text {n }}$ de weerstand was gebroken"; dat Tiow m. z. Siri Sori.

's-Gravenhage, October 1913. 


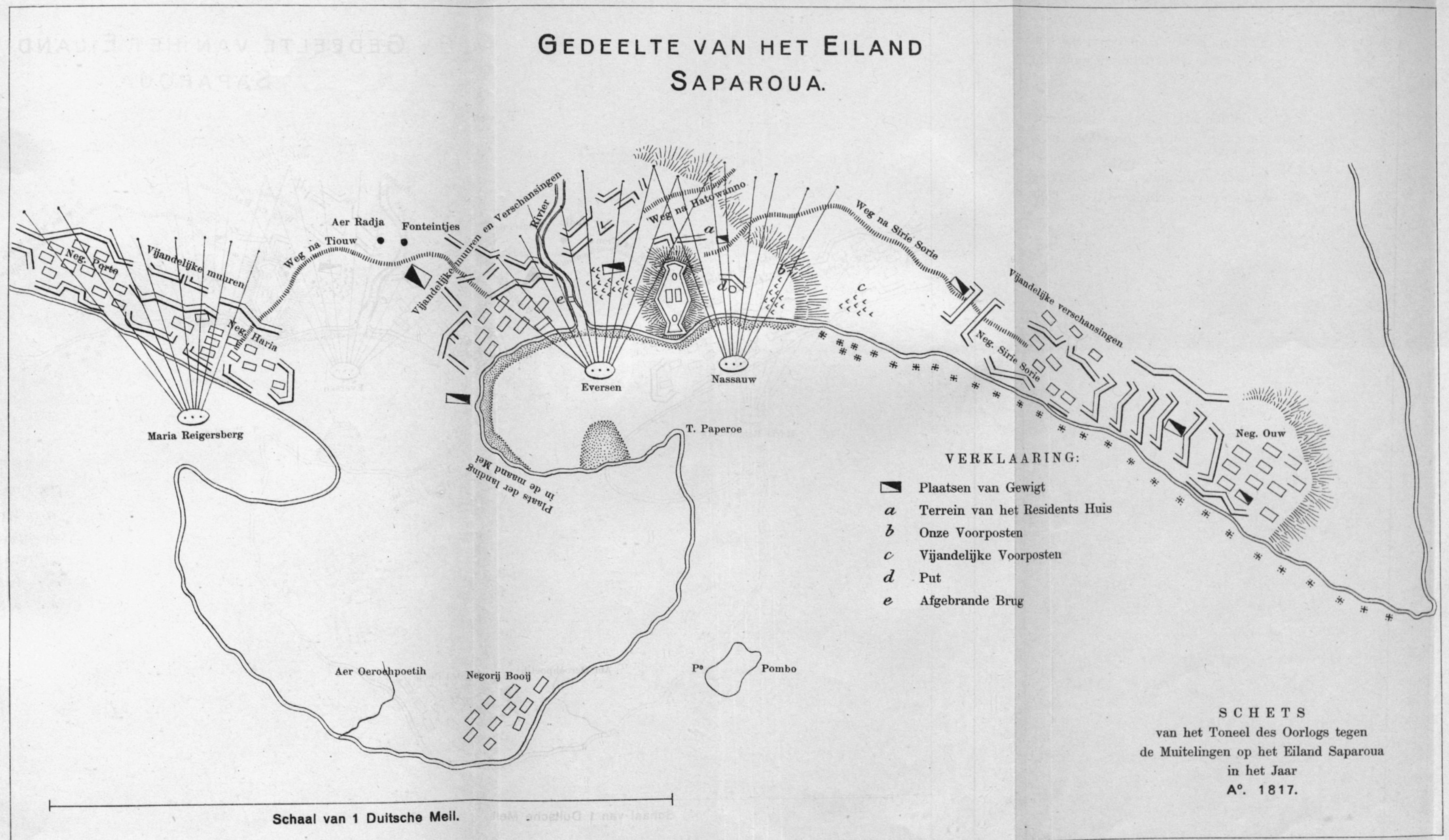

